\title{
Legal and contractual implications of the informal admission of psychiatric patients
}

\author{
Ikechukwu Obialo Azuonye
}

The lack of official consideration of the legal and contractual implications of the informal admission of poychiatric pationts has resulted in a stuation in which individual hospltals and mental nursing homes have generated their own mistaken assumptions about the nature of this form of admission, often to the detriment of patients.

Section 131 (1) of the Mental Health Act 1983 states:

"Nothing in this Act shall be construed as preventing a patient who requires treatment for mental disorder from being admitted to any hospital or mental nursing home in pursuance of arrangements made in that behalf and without any applications, order or direction rendering him liable to be detained under this Act, or from remaining in any hospital or mental nursing home in pursuance of such arrangements after he has ceased to be so liable to be detained."

This is a rather long-winded way of saying that psychiatric patients can be admitted informally and, in the case of detained patients, remain in hospital informally when the compulsory powers under which they are detained are discharged.

The historical background to the concept of informal admission is interesting. Section 5 (1) of the Mental Health Act 1959 makes exactly the same provisions as appear under Section 131 (1) of the 1983 Act. This Section of the 1959 Act was included because, prior to that time, it was not possible for psychiatric patients to be admitted without the fulfilment of legal formalities. "Voluntary" patients had to sign a form requesting admission. If they wished to leave hospital, they had to give 72 hours' notice, in writing, of their intentions. In her commentary on the Mental Health Act 1959, Kathleen Jones (1972) wrote:

"Since the patient's volition is no longer required, this Section can be taken to cover a large section of mental patients who have no power of volition. provided they do not positively object to treatment."

This is a viewpoint echoed in paragraph 1-141 subs (1) of Richard Jones's Mental Health Act Manual (1991):
"The Admission is informal, and not voluntary. In other words, it is not necessary for the patient to express his consent to the admission. It is therefore possible to admit a patient on an informal basis as long as that person is not indicating either verbally or through his actions that he objects to the admission. The Royal Commission stated that patients should be assumed to be content to enter hospital unless they positively object. ${ }^{\cdots}$

Thus, informal admission is the reception into hospital of a patient who either positively consents to admission or does not positively resist being taken into hospital. Having provided for informal admission, the Mental Health Act 1983 does not offer, as one might have expected. a statement of the effects (the legal and contractual implications) of such admission. The Memorandum to Parts I to VI, VIII and X of the Mental Health Act 1983, in its paragraph 272. offers that:

"Informal admission should continue to be the normal mode of admission to hospital, and should be used whenever a patient is not unwilling to be admitted. and can be treated without the use of compulsory powers (see Section 13). If compulsory detention becomes necessary in the case of an informal patient, an application can be made under Section 5 . No hospital should have a rule specifying times of day when only formal patients will be admitted."

The only effect of informal admission specified in the Memorandum is therefore that an informal patient can subsequently be detained. The Code of Practice (Department of Health \& Welsh Office. 1994) does make reference to informal admission, but only to state that it ought to be possible.

Since it is the case that neither in the Mental Health Act 1983, its Code of Practice nor in the explanatory Memorandum is there any reference to the effects of informal admission, a custom and tradition has evolved to the effect that informal patients are free to come and go as they please'. This has been an issue for the Mental Health Act Commission, community health councils and Mental Health Act managers whenever it has been felt that any hospital's 
policies got in the way of informal patients' right to complete freedom of movement and conduct.

I have searched for the source of the idea that informally admitted psychiatric patients are as free as many health care professionals appear to believe. The closest I have come to it is the statement, in paragraph 1-140 of Richard Jones's Mental Health Act Manual (1991) that "Subject to s.5, informal patients have the right to leave hospital when they like", and "Once an informal patient has been admitted to hospital no person or body is placed under any legal obligation to inform him of his legal status and the fact that he is free to leave hospital whenever he wishes". Jones does of course draw attention to Section 5 in these passages, and does point out later in this paragraph that ". . . circumstances can arise which justify the use of compulsion on a 'willing' patient . . .., but I suspect that people have simply seized upon the phrases which convey the informal patients' ". . . right to leave hospital when they like" to justify a laissez-faire, inappropriately liberal attitude which, to all intents and purposes, disregards the duty of care to informal patients.

Surely, if a patient is as free as all that, he might as well be at home! Has not a volitional informal patient agreed, by virtue of accepting admission, to abide by the rules of the ward including observing meal and medication times, participating in ward activities, not bringing drugs, alcohol or weapons on to the ward, refraining from unprovoked attacks on other patients and staff, not destroying hospital property? Should not the nursing staff be able to record when an informal patient is going off the ward, where he is going to, and when he is to be expected back on the ward? Would it not be expected that the nursing staff should quickly assess if an informal patient who wishes to leave the ward is in a fit state to be allowed out? Does it not greatly distress relatives if they telephone the ward and the staff do not know if the patients concerned are on the ward or not? In the event that something goes wrong, do enquiry panels not ask for details of the patients' comings or goings? In other words, is it not in the best interests of informal patients that they should not be free to do whatever they like?

My own views are contained in the questions themselves, but I wanted other viewpoints. So, I sent letters to the Royal College of Psychiatrists. the Medical Protection Society, the Legal Department of the British Medical Association, the Mental Health Act Commission, the Mental Health and NHS Community Care Division of the NHS Executive, the United Kingdom Central Council for Nursing, Midwifery and Health Visiting (UKCC) and the Social Services Department, London Borough of Lambeth (because my NHS base is in Lambeth) requesting their views on the effects of informal admission to psychiatric hospitals and mental nursing homes. Their responses (all in February 1997) are quoted below:

\section{Royal College of Psychiatrists}

(Dr Robert E. Kendell, President, “. . . expressing (his) own views rather than the formal opinion of the College")

The legal situation is exactly the same as that of patients admitted informally to all NHS hospitals or indeed to all NHS facilities. Patients do not have the right to come and go as they please'. If a patient is not co-operating with treatment. the consultant responsible for their care has to decide - preferably in consultation with other members of the clinical team - whether any good purpose is being served by continuing to allow that patient to remain in hospital. If the consultant decides that the patient's insistence on 'coming and going as they please' makes it impossible for the original aims of admission to hospital to be achieved, or even creates a situation in which the resources embodied in the NHS bed in question would be better used by some other patient. then the psychiatrist is perfectly entitled to discharge the patient.

He would be well advised, though, to record his reasons for discharging the patient in the patient's case notes in some detail, and inform the GP and other interested parties accordingly. Sometimes, though, the alternative to allowing a patient to 'come and go as they please' should be to detain them in hospital under the terms of the Mental Health Act rather than to insist that they either collaborate with treatment or leave".

\section{British Medical Association}

\section{(Ann Sommerville, Head of Medical Ethics)}

"The effects are the same as any admission to hospital for treatment of either a physical or mental condition, where the patient has agreed to admission or had not objected and is accepting treatment. The distinction to be made is with compulsory admission under the Mental Health Act 1983, where the patient is admitted and detained in hospital against his/her wishes, and can then be treated for mental disorder without consent.

I enclose an extract from Richard Jones's Mental Health Act Manual (5th edition) which gives a commentary on section 131 of the Mental Health Act. As you will see, this section is designed to ensure that nothing in the Act prevents informal admission where this is appropriate. This commentary gives a number of references which are helpful.

The comment that informal patients appear to 'have the right to come and go as they please' is not quite accurate. It will be a matter of clinical judgement as to whether a request for a patient's informal admission to hospital will be granted. As with any other patient, an informal psychiatric patient has the right to discharge him/herself at 
any time. However, there are provisions in the Act (Sections 5(2) and 5(4)) whereby a registered medical practitioner or a 'nurse of the prescribed class' can prevent an informal patient from leaving hospital, in order to allow time for an assessment for compulsory detention under the Mental Health Act to be carried out. The grounds for detention would then have to be fulfilled for the patient to be kept in hospital once the time limits for the holding powers under sections 5(2) and 5(4) have elapsed.

While in hospital, an informal patient cannot be given treatment without his/her consent. If treatment is refused, it would again be a clinical decision as to whether alternative forms of treatment are offered, or whether the patient is to be discharged from hospital".

\section{Medical Protection Society}

(Dr Sherry P. Williams, Senior Medico-Legal Adviser, offering "personal advice to (me) rather than a policy statement of the MPS")

"Section 131 of the Mental Health Act 1983 simply states that the provisions of the Mental Health Act with regard to compulsory admission to hospital in no way precludes a patient being admitted to hospital for treatment on an informal basis, i.e. voluntarily. In such circumstances, if a patient decides to take his own discharge. sometimes contrary to medical advice, then that is the prerogative of the patient as there is no statutory authority to prevent the patient from leaving as would be the case if he was detained under the appropriate section of the Mental Health Act.

In your letter, you referred to informal patients having 'the right to come and go as they please', and although their (admission) is not compulsory, it must be a matter of agreement between those providing care and treatment for the patient to determine the basis of the informal admission. If a patient is unwilling to comply with the treatment plan which requires their presence in the hospital, then it is unlikely that the patient will benefit from the treatment and therefore informal admission may come to an end. Alternatively, it may be necessary to consider the compulsory detention of the patient".

\section{Mental Health Act Commission}

\section{(Mr William Bingley, Chief Executive)}

"May I refer you to the commentary under Section 131 in the Mental Health Act Manual (5th edition. Sweet and Maxwell) by Richard Jones, on page 338 , which I think you will find helpful. You are quite right that very limited reference to informal admission is made in the Code of Practice - as you will recall Section 118 of the Mental Health Act 1983 confines the Code of Practice to giving advice about compulsory admission to hospital and the medical treatment of patients suffering from mental disorder'. In essence, I think, informal patients do 'have the right to come and go as they please'. In essence. they are in the same position as any other kind of hospital patient. The key difference is, of course, that mental health professionals, unlike other healthcare professionals, possess certain powers under the Mental Health Act to stop informal patients leaving the hospital and consequently they are under an obligation to consider their use in those circumstances where such powers might be applicable".

\section{United Kingdom Central Council for Nursing, Midwifery and Health Visiting (UKCC)}

(Mr Richard Bradshaw, Professional Officer, Mental Health and Learning Disability)

"Nurses are professionally accountable for ensuring that they 'always act in such a manner to promote and safeguard the interests and well being of patients and clients'. This responsibility should be explicitly linked to the assessed needs of an individual patient. If patients are receiving informal care in an inpatient setting, nurses should take due account of the safety needs of the individual, the wider ward client group and other staff members.

In terms of patients having 'the right to come and go as they please', this right has to be framed within the context of the risk assessment applied by the staff. If patients are considered to be at risk to themselves or others, then medical and nursing staff would apply as necessary any powers given to them under Section $5(2)$ and 5(4) respectively.

If clients or patients are disruptive or engage in unacceptable behaviours, not as a consequence of mental illness, and which has not responded to behavioural or other sanctions, an organisation may wish to consider to what extent it will tolerate these behaviours in the wider interests of other patients, visitors and staff. I know that some organisations have explicitly notified clients of what behaviours are unacceptable (racism. sexism. inpatient alcohol use, etc.). How organisations then choose to interpret and enforce such aims is a matter for local policy. The key issue for nurses in these circumstances is that actions are coherent, well documented and, above all, justifiable.

Under certain circumstances, practitioners may consider withdrawing care from patients and this is more fully covered in the document Guidelines for Professional Practice".

\section{NHS Executive Headquarters, Department of Health (London)}

(Dr Sheila Adam, Head of Mental Health and NHS Community Care)

"Informal mentally disordered patients who are accepting treatment have the same rights as other NHS patients whilst in hospital. They also have the same responsibilities. In practice, this means that informal mentally disordered patients should not be allowed to 'come and go as they please', but any reasonable request should be met if staff agree that this would be in the patient's best interest.

Informal patients have the legal right to discharge 
themselves from hospital unless the criteria for detention under the Mental Health Act 1983 are met".

\section{Social Services Department, London Borough of Lambeth}

(Ms Irene Stiller, Approved Social Worker/ Resource Manager, expressing her "personal views (which) are not representative of any Lambeth Social Services policy or viewpoint")

\begin{abstract}
"My views regarding the right of informal patients to 'come and go as they please' are mixed . . . The question of the right to refuse treatment is obviously a problem. It begs the question as to what is the point of going into hospital. How can you assess a patient who is never there? If you cannot treat (him) and the person walks out or discharges himself, you (find yourself) in the same round of events again".
\end{abstract}

\section{Conclusion}

There is a great deal of confusion about the legal and contractual implications of the informal admission of psychiatric patients (that is, people suffering from mental disorders with or without concomitant physical illnesses). This is most sharply reflected in the widely held, and variously interpreted, notion that informal patients "are free to come and go as they please". Many patients, prior to accepting informal admission, request (and are often given) the (false) assurance that they will have complete freedom while in hospital, and will be able to take their own discharge at any time. They justifiably feel betrayed when they try to leave hospital only to find themselves being prevented from doing so (Section 5(4) or 5(2)). A significant proportion of informal patients cite their admission status as giving them a carte blanche to do what they like. while many health care professionals, misunderstanding the nature of informal admission, permit the more anti-social types of patients to use and abuse the service.

It is very surprising, given that most patients are admitted informally, that no one, not even the Royal College of Psychiatrists, has ever formally considered the issue of informal admission. So, individual psychiatric units, without a dependable reference point, have generated their own ideas and assumptions about the administration of this type of admission.

The contributions put together in this paper make the position clear: informal admission to psychiatric hospitals and mental nursing homes is the same as informal admission to any other NHS facility, in so far as the patient has either agreed to go into hospital, or has not refused to do so. Whereas the informal physically ill person may refuse treatment or discharge him/herself at any time if he or she does not also suffer from a mental disorder of a nature and degree which makes him or her liable to detention in hospital. if the informal psychiatric patient decides to disregard ward rules and procedures, refuse treatment or discharge him/herself, the law requires that "... . consideration must be given to assessing whether they would more appropriately be formally detained" (Paragraph 18.27. Code of Practice 1993). He/she can be prevented from leaving hospital (under the provisions of Section 5(2) and 5(4) of the Mental Health Act 1983) and may subsequently be detained on longer-term orders such as Section 2 or Section 3 with a view to continuing his/her assessment and, if necessary, enforcing treatment.

This requirement of the law, and good practice, make it necessary for the informal patient to be seen by a member of staff each time he/she wishes to go out of the ward. whether he intends to return to the hospital or not, to ensure that he/she is in a safe state of mind to do so (a 'walk' to the local shops may evolve into a train journey to a place far from the hospital). The extent of this brief evaluation would depend on the situation: it could be argued that more would be expected in the case of acutely psychotic patients than rehabilitation patients who have been settled for a long time and have been using long periods of leave in the community. But it is my view that nursing and/ or medical staff should be able to feel satisfied that any patient, irrespective of the stage of his or her treatment, can safely go out of the hospital before allowing him or her to do so (there has been a recent case of a young man who went on a walk from his long-term rehabilitation ward and ended up carrying out an armed robbery).

We infer, from this discussion that informal psychiatric patients do not, in fact, have the right to total freedom of movement and action. Hospitals and mental nursing homes must therefore see to it that the true nature of their type of admission, and what the staff have to do to fulfil the law, are made as clear as possible to informal patients. Hospitals and mental nursing homes must also see to it that they have in place mechanisms to ensure that informal patients are seen, and (however briefly) evaluated by members of staff each time they wish to go out of the ward. How they do this is up to them but I do know that some hospitals have addressed this by the use of buzzer systems/electronic locks to let people into and out of 'open' wards, an approach I personally commend.

The Royal College of Psychiatrists should consider (jointly with the NHS Executive of the Department of Health) setting up a Working Party on the Informal Admission of Mentally Disordered Patients to review all the issues 
relating to informal admission, and to produce a College policy statement. Further, psychiatric hospitals and mental nursing homes should put in place written policies about the administration of informal admission, just as they have written policies about every other aspect of the care of patients, to fulfil not only the duty of care, but also the legal and contractual implications of this type of admission.

\section{Acknowledgements}

I am grateful to Dr Robert Kendell, Mr William Bingley, Dr Sherry Williams, Mr Richard Bradshaw, Dr Ann Sommerville, Dr Sheila Adam and Ms Irene Stiller for taking the trouble to respond to my initial enquiry, and for their kind permission to include their personal communications in this paper.

\section{References}

DEPARTMENT OF HEALTH AND SOCIAL SECURTTY (1987) Mental Health Act 1983-Memorandum to Parts I to VI. VIII and $X$. London: HMSO.

DEPARTMENT OF HEALTH \& WELSH OFFICE (1994) Mental Health Act-Code of Practice. London: HMSO.

JONES. K. (1972) A History of the Mental Health Services. London: Routledge and Kegan Paul.

JONES, R. M. (1991) Mental Health Act Manual. London: Sweet and Maxwell.

Ikechukwu Obialo Azuonye, Consultant Psychiatrist/Senior Lecturer, Adult Mental Health Unit, Lambeth Healthcare NHS Trust, 108 Landor Road, Stockwell, London SW9 9NT

\title{
FORTHCOMING FROM GASKELL
}

\section{ClinicalTopics in Psychotherapy}

\author{
Edited by Digby Tantam
}

The focus of this book is on specific conditions in which psychotherapy is the main treatment currently in use. Common syndromes which patients present to the psychotherapist and to general psychiatrists are covered. Contributors provide a succinct review of what treatment works in each condition, and how it works. Some of the chapters have been published previously in the British Journal of Psychiatry.

READERSHIP: Psychotherapists, general psychiatrists, general practioners, and all those whose profession involves the provision of psychological treatment

August 1998, £30.00, 304pp, Paperback, ISBN 1901242226

Royal College of Psychiatrists, 17 Belgrave SQuare, London SW1X 8PG TEL: +44 (0) 171235 2351, EXT 146 FAX: +44 (0) 1712451231 http://wwiv.rcpsych.ac.uk 